This is the author's draft version of a manuscript that is now in press at Perspectives on Psychological Science

\author{
Rethinking Executive Function Development \\ Sabine Doebel* \\ Department of Psychology, George Mason University
}

*Corresponding author (sdoebel@gmu.edu) 


\begin{abstract}
Research on executive function in early childhood has flourished in recent years. Much of this work is premised on a view of executive function development as the emergence of a set of domain general component processes (e.g., working memory updating, inhibitory control, and shifting). This view has shaped how we think about relations between executive function and other aspects of development, the role of the environment in executive function development, and how best to improve executive function in children who struggle with it. However, there are conceptual and empirical reasons to doubt that executive function should be defined in this way. I argue executive function development is better understood as the emergence of skills in using control in the service of specific goals. Such goals activate and are influenced by mental content like knowledge, beliefs, norms, values, and preferences that are acquired with development and are important to consider in understanding children's executive function performance. This account better explains empirical findings than the components view; leads to specific, testable hypotheses; and has implications for theory, measurement, and interventions.
\end{abstract}




\section{Rethinking Executive Function Development}

\section{Importance of executive function development}

Executive function is fundamental to human cognition and achievement - we use it when we need to exercise control over our thoughts and behavior, especially when we are trying to do something that competes with our habits, impulses, and desires. More formally, it often has been defined as the use of (higher) cognitive processes to engage, direct, or coordinate other (lower) cognitive processes, typically in the service of goals (e.g., Miyake, Friedman, Emerson, Witzki, Howerter, \& Wager, 2000; Zelazo, 2004). However, in recent years it has also been increasingly defined reductively as a set of separable but related component processes involved in goaldirected thought and action. Often this is specified as three "executive functions": updating working memory, shifting between task sets, and inhibition of prepotent thoughts and responses (e.g., Best \& Miller, 2010; Diamond, 2013; Miyake et al. 2000), but other proposals also exist (e.g., Carlson \& Moses, 2001; Miyake \& Friedman, 2012; Simpson \& Carroll, 2019).

Over the past several decades, executive function research has flourished in developmental psychology. Performance on executive function measures improves with age in early childhood (Best \& Miller, 2010; Carlson, 2005), even when taking into account other factors like verbal knowledge and IQ (e.g., Carlson \& Moses, 2001; Zelazo et al., 2015); and numerous studies have found concurrent and longitudinal relations between child executive function measures and measures of diverse skills and outcomes (e.g., academic achievement, and social, logical, biological reasoning; Best, Miller, \& Naglieri, 2011; Blair \& Razza, 2007; Carlson \& Moses, 2001; Doebel, Rowell, \& Koenig, 2015; Richland \& Burchinal, 2013; Zaitchik, Iqbal, \& Carey, 2013). Executive function deficits are linked to a range of clinical outcomes (e.g., ADHD, autism, depression, Pennington \& Ozonoff, 1996; Snyder, 2013). Thus, 
two key goals of psychological science are understanding how executive function develops and can be improved.

\section{Executive function development as the emergence of executive function components}

Executive function development is widely understood as improvements in domain general components that are thought to underlie self-regulatory and complex goal-directed behaviors, which in turn are subserved by prefrontal cortical development (Diamond, 2013; Miyake et al., 2001). Correspondingly, executive function is also thought to be best understood in isolation from the particulars of the task situation (e.g., Carlson \& Moses, 2001; Miyake et al, 2000; Miyake \& Friedman, 2012). Some historical context can elucidate why. Research on executive function has a long history, with origins in neuropsychology and the desire to understand the cognitive capacities and impairments of patients with frontal lobe injury. Some of this can be traced to the at least partly apocryphal story of Phineas Gage, who, after experiencing extensive injury to one of his frontal lobes following a work accident, showed a pattern of behavioral changes across numerous life domains suggesting impaired self-control (Damasio, Grabowski, Frank, Galaburda, \& Damasio, 1994). In adults, tasks nominated as "executive function tasks" have typically been linked with frontal lobe injury (e.g., the Wisconsin Card Sort Task and Color-Word Stroop) and many common child executive function tasks can be thought of as adaptations of these tests (e.g., Dimensional Change Card Sort and Day-Night Stroop; Zelazo, 2006; Gerstadt, Hong \& Diamond, 1995). A key utility of these measures is that they provide an unambiguous signal that prefrontal cortex and executive function are involved in some cognitive operation (e.g., when a frontal patient or young child persists with an incorrect response in the face of clear opposing feedback; Demakis, 2003; Zelazo, 2006). For example, in the Dimensional Change Card Sort, children must sort cards by one dimension (e.g., shape) for 
several trials before being asked to switch and sort the same cards by another dimension (e.g., color). Three- and four-year-olds typically persist (or "perseverate", in neuropsychological terminology) in sorting the cards by the old dimension, despite rule reminders and knowledge of how to sort by each dimension, whereas typically developing children five years and older tend to switch easily (Doebel \& Zelazo, 2015).

Prior to the seminal work of Miyake and colleagues (2000), definitions of executive function proliferated that bore family resemblances to one another but were often complex. There was also a 'homunculus' problem in which executive function was explained by positing what could be thought of as an agent-like entity that was responsible for coordinating control processes, (e.g., "the central executive"; Baddeley \& Hitch, 1974). Miyake et al. addressed these issues by examining the structure of executive function via latent variable analysis. One rationale was that by examining executive function using multiple measures and extracting latent variables, one can be sure they are getting the signal of executive function(s) instead of noise that is due to various idiosyncratic task demands (e.g., task-specific motor and conceptual knowledge demands). Critically, they focused on measures of particular posited executive functions inhibition of prepotent responses, set-shifting, and updating working memory - in part because these were relatively simple to operationalize and there were already numerous measures of each putative executive function that could be drawn on for latent variable analyses (Miyake et al. 2000). This work identified separate factors mapping to each set of tasks measuring the three executive functions, and a common factor ('common executive function') that is highly heritable (Friedman, et al., 2008) ${ }^{1}$. Developmental researchers have undertaken similar analytic approaches to investigating the structure of executive function in childhood (e.g., Wiebe, Espy,

\footnotetext{
${ }^{1}$ The reported heritability of executive function rests on several assumptions, including that it is a latent factor that is best captured by certain lab tasks and by eliminating task-specific variance.
} 
\& Cherak, 2008; Wiebe et al., 2011). Even without latent variables, executive function lab tasks are commonly thought to be abstracted from real-world motivational contexts (Zelazo \& Carlson, 2012) and made more reliable and "pure" via the construction of composite measures (Carlson \& Moses, 2001). On the basis of such work, it has been suggested that executive function may be reducible to one to three component processes that may become more differentiated with age (Karr, Areshenkoff, Rast, Hofer, Iverson, \& Garcia-Barrera, 2018).

Performance on child executive function tasks is associated with prefrontal cortical development (Diamond, 2013), and there are dramatic changes in executive function task performance and prefrontal development in young children (e.g., Bunge \& Zelazo, 2006; Hodel, 2018). Accordingly, executive function has been suggested to develop through a number of theorized neurocognitive mechanisms like inhibition (Kirkham, Diamond, \& Cruess, 2003), changes in consciousness and reflection (Marcovitch \& Zelazo, 2009; Zelazo, 2004), active maintenance of abstract representations (Munakata, Chatham, \& Snyder, 2012), and interactions between frontal and posterior brain regions (Buss \& Spencer, 2018). These developmental cognitive neuroscience accounts share an emphasis on endogenous, neural mechanisms supporting the emergence of executive function component processes.

These component processes have been theorized to underlie self-regulatory behavior broadly. Countless empirical articles on executive function development begin with statements to this effect (e.g., Buss \& Spencer, 2014; Blair \& Razza, 2007; Doebel, Dickerson, Hoover, \& Munakata, 2018; Friedman \& Miyake, 2012). For example, Diamond (2012) writes:

There is general agreement that there are three core EFs...Inhibition is important for...controlling one's behavior -for example, by overriding habitual responses, exerting self-control (i.e., resisting temptations...). 
Along similar lines, executive function tasks measuring putative components have been viewed as assessing executive function at a relatively low level, and thus as building blocks for more complex executive function skills, like planning (e.g., Diamond, 2012; Miyake, et al., 2001). How this view of executive function development has shaped thinking about how it relates to other processes, the role of environment, and how to improve it

Relations between executive function and other aspects of development tend to be explained reductively, with the assumption that executive function component processes develop and are applied to specific cognitive developmental domains. For example, executive function has been proposed as a mechanism underlying cognitive developments such as analogical reasoning (Richland \& Burchinal, 2013), theory of mind (Carlson \& Moses, 2001; Devine \& Hughes, 2014), and mature biological reasoning (Zaitchik, Iqbal, \& Carey, 2013). Executive function components are also proposed to underlie socioemotional development and academic skills (Diamond, 2013; Bull, Espy, Wiebe, Sheffield, \& Nelson, 2011).

Conceptualizing executive function development as improvements in component processes has also influenced how researchers think about the role of the environment in executive function development. In interpreting associations between socioeconomic status and executive function task performance in children, for example, researchers have used 'disparity' models that focus on factors like neglect and poverty as interfering with healthy brain development, leading to broad executive function deficits in children of lower socioeconomic status backgrounds (e.g., Hackman, Gallop, Evans, \& Farah, 2015; Hodel, 2018). Similarly, associations between language and executive function in childhood (e.g., Carlson \& Moses, 2001) have been explained in terms of influences of language on neurocognitive mechanisms 
underlying executive function development (e.g. Alderson-Day \& Fernyhough, 2015; Diamond, Barnett, Thomas, \& Munro, 2007; Kirkham, Cruess, \& Diamond, 2003).

This conception has also influenced ideas about how executive function can be improved. Numerous studies have tested the possibility that executive function can be improved in children (and adults) broadly by exercising executive function components on lab tasks or via particular activities thought to require executive function, like switching between two languages, engaging in pretend play, and doing martial arts (Bialystok, 2001; Lillard et al., 2013; Diamond, 2012), or by supporting underlying developmental mechanisms like reflection (e.g., Espinet, Anderson, \& Zelazo, 2013; Zelazo, Forston, Masten, \& Carlson, 2018). Improvements in executive function components are then expected to lead to improvements in related domains that require executive function (e.g., so-called "transfer"). Others working within the disparity framework have targeted factors like parenting skills, nutrition, and even economic factors that likely support healthy brain development and, in turn, executive function (e.g., Noble, 2017; Obradovic et al., 2018). School curricula have been developed to support socioemotional and academic skills by teaching skills that are thought to develop executive function components (e.g., PATHS and Tools of the Mind curricula; Bodrova \& Leong, 2006; Riggs, Greenberg, Kusche, \& Pentz, 2006).

\section{Problems with this view of executive function development}

There are empirical and conceptual reasons to doubt that executive function can be reduced to a few component processes that support other developmental phenomena or selfregulation broadly. First, evidence that exercising putative executive function components improves executive function or abilities in other domains is limited. The accumulating literature suggests lab-based executive function training may not be effective, at least not at obtaining "far 
transfer" - improvement in related but different domains (Kassai, Futo, Demetrovics, \& Takacs, 2019), which is the holy grail of cognitive training. Such training typically involves multiple sessions in which a child completes executive function tasks that ostensibly engage and exercise one or more executive function components (e.g, Johann \& Karbach, 2019; Pozuelos, Combita, Abundis, Paz-Alonso, Conejero, et al., 2019). Well-powered training studies with adults often show no evidence of transfer and even sometimes show positive evidence of a lack of transfer (e.g., de Simoni \& von Bastian, 2018). In addition, some of the early school curricula findings have not replicated (e.g., Wilson \& Farran, 2012). Moreover, findings that bilingualism, pretend play, and martial arts strengthens executive function are in dispute (e.g., von Bastian, Souza, \& Gade, 2016; von Bastian, De Simoni, Kane, Carruth, Coyle et al., 2018; Lillard et al., 2013; Mercer, 2011).

Second, there is mounting evidence that canonical lab executive function tasks do not consistently relate to questionnaire measures of self-regulation (Duckworth \& Kern, 2011; Saunders, Milavskaya, Etz, Randles, \& Inzlicht, 2018; Toplak, West, \& Stanovich, 2013) or many real world outcomes of interest, even at the level of latent variables (Eisenberg et al., 2019; but see Friedman \& Banich, 2019). This seems to undermine the notion that executive function components, which are thought to be best measured by standard lab tasks, play a role in supporting self-regulation broadly.

Third, while correlations between performance on executive function lab measures and other outcomes are often cited as evidence that executive function components support these outcomes, it is difficult to draw strong conclusions from such work. In many analyses only a single executive function lab measure is included (see Devine \& Hughes, 2014 for examples), and therefore it is problematic to conclude that covariation between performance on that measure 
and that of another construct, like theory of mind, is indicative of the role of an executive function component. Correlational and longitudinal studies also often do not adequately address third variable explanations. If covariates are included, they are often noisy approximations of constructs (e.g., using a single vocabulary measure like the Peabody Picture Vocabulary Test to account for individual differences in language skills), thus confounds usually are not well controlled, making it difficult to draw causal conclusions (Westfall \& Yarkoni, 2017). Thus, correlations between executive function measures and outcomes, even in the presence of covariates, are not compelling evidence that executive function components play a mechanistic role in those outcomes.

Finally, closer examination of the origins of the components view casts severe doubt on the notion. Researchers routinely cite Miyake et al. (2000) as evidence that executive function is three components, but this is not what the paper demonstrates. As already noted, Miyake et al. focused on the three putative executive functions in part due to practical considerations, and it is reasonable to assume that if additional sets of tasks were added to a latent variable analysis in order to account for other posited executive functions (e.g., planning or delaying, for example) one might obtain a new pattern of results with additional differentiable components, e.g., for planning or delaying (see Karr et al., 2019 for a similar argument). In other words, the separable components identified in latent variable analyses may reflect common task demands of the exemplars in the task class (e.g., all shifting tasks require using control in order to shift between mental operations) rather than the structure of executive function per $\mathrm{se}^{2}$

\footnotetext{
${ }^{2}$ Miyake and colleagues have themselves shifted to a unity/diversity framework that emphasizes a common higherorder factor ('common EF') that may reflect goal maintenance capacity, and updating and shifting as nested factors, while acknowledging that executive function components shouldn't be reified but rather reflect the utility of certain measures in understanding individual differences (Miyake \& Friedman, 2012).
} 
Similarly, claims have also been made that executive function in early childhood is unitary and later differentiated into components (Wiebe et al., 2008; 2011), despite the fact that different tasks have been used with children, with some task classes being omitted entirely (e.g., shifting). Contrary to strong claims about the ontology of young children's executive function, it is reasonable to assume that if suitable measures of shifting (or planning, delaying, etc.) were included in confirmatory factor analyses of data from young children, then additional factors might be identified.

The components view is further challenged by a recent systematic examination of the accumulated data. In child and adult samples there is inconsistency in the number of executive function components identified. Three-factor models (and other models) of executive function are often rejected as a poor fit to the data (Karr et al., 2018). Even tasks that are commonly used to measure a single putative executive function component like inhibitory control do not always correlate well or load onto a single factor (Gartner \& Strobel, 2019).

\section{An alternative view: executive function development as skills in using control in the service of specific goals}

If executive function development is not the emergence of a set of domain general components, then what is it? I suggest that instead of thinking of executive function development as the emergence of separable components that can themselves be meaningfully separated from "task-specific demands", we ought to think of it as the development of skills in using control in the service of specific goals. Critically, specific goals activate mental content like relevant knowledge, beliefs, values, norms, interests, and preferences that children acquire with development and that shape how they use control. Knowledge may include specific concepts that make a particular goal more appealing or easy to keep in mind (e.g., mental state concepts that 
help one tune into others' expectations or desires, Wellman, Cross, \& Watson, 2001); relevant motor, procedural, and embodied knowledge (Goldstein \& Lerner, 2018; Lillard, 2016); verbal concepts, skills, rules or strategies (Doebel, Dickerson, Hoover, \& Munakata, 2018; Winsler, Fernyhough, \& Montero, 2009); and even knowledge about others' control behavior (Leonard, et al., 2018). Beliefs may include ideas about how one's group behaves in relation to similar goals (e.g., Doebel \& Munakata, 2018) or expectations about the likely benefits or consequences of using control (Kidd, Palmieri, \& Aslin, 2013; Michaelson \& Munakata, 2016). Values and norms may include ideas about when and how control should be used (e.g., Doebel \& Munakata, 2018; Carlson \& Zelazo, 2011; Lamm et al., 2018). Interests and preferences may include inclinations towards certain activities or stimuli (Lillard, 2016). Such content, rather than being noise to partial out or generalize over, should be taken into account when trying to understand how children develop executive function. Thus, on this view, well-established age-related improvements on executive function tasks may in part reflect the acquisition of knowledge, beliefs, values and more that shape how control is used in the service of particular goals.

For example, on this proposal children do not simply develop an inhibitory process that they then apply across a wide range of situations. Rather, they develop skill in engaging control in specific ways in the service of specific goals, such as avoiding hitting a playmate who takes one of their toys (Figure 1). This occurs in part due to things like: knowledge of what it feels like to get hit by someone and awareness of others' capacity to feel pain; values related to avoiding harming others; knowledge of socially acceptable alternatives to hitting; social skills to retrieve a toy without hitting; beliefs that one may be scolded for engaging in hitting; and more. As another example, children may develop skill in using executive function to coordinate different mathematical operations like adding and subtracting in part by consolidating relevant conceptual 
knowledge (e.g., what it means to add and multiply things) and procedural knowledge (e.g., practice doing each operation). And, as prior work suggests, children may use executive function more effectively in the service of such operations when the task situation is concrete and meaningful (e.g., working out the amount of change to give to a customer; Saxe, 1998). Thus, executive function on this view simply cannot be reduced to component processes that are isolable from specific task goals and the diverse mental content that invariably comes into play.

A)

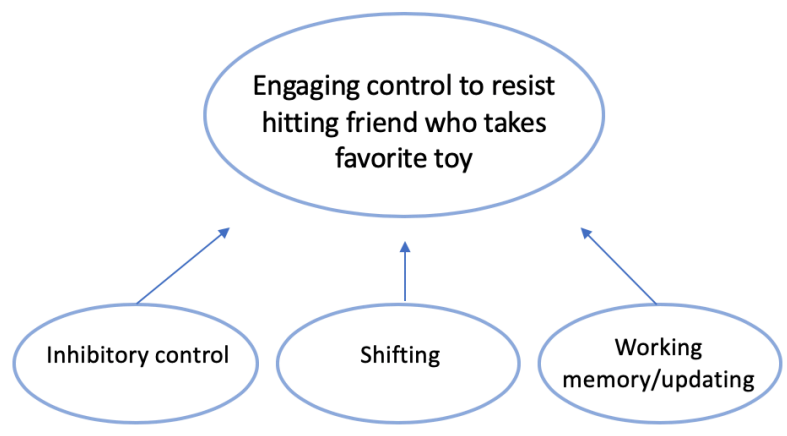

B)

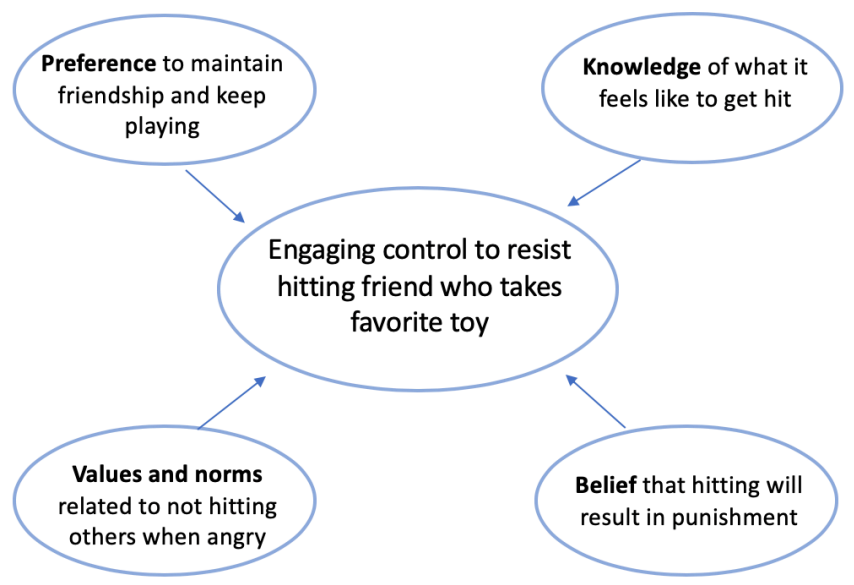

Figure 1. Contrasting views of executive function development. (A) Diagram of the prevalent view that executive function component processes develop endogenously and support development in various domains, such as self-regulation vis-à-vis peers (avoiding hitting a friend who takes a favorite toy). Here, support for brain development is expected to strengthen components, and, in turn, help children self-regulate. For example, on this view a child may use their inhibitory control ability to inhibit hitting their friend, and may use their shifting ability to shift to playing with another toy instead. (B) Diagram of proposed view, where engaging control is not decomposed into or explained in terms of components; rather, one simply engages control in a particular way, which is enabled by mental content that is acquired with development, like values, norms, beliefs, knowledge, preferences, and more. This conception is neutral about how executive function is instantiated at the neurological level.

This account does not imply that executive function is nothing more than the knowledge, beliefs, values and more that are activated by a particular goal. Evidence suggests that executive function measures (especially latent variables or composites) tap stable individual differences (Carlson \& Moses, 2001; Friedman et al., 2008; Friedman et al., 2011), which may reflect differences in a basic capacity to maintain goal information (Miyake \& Friedman, 2012). These individual differences are in turn influenced by various factors like sleep, stress, nutrition, drug 
use, and overstimulation (e.g., Carter et al., 2010; Lillard, Drell, Richey, Boguszewski, \& Smith, 2105; Obradovic, et al., 2019; Peterson, Rothfliesch, \& Zelazo, 1990; Turnbull, Reid, \& Morton, 2013). Targeting executive function via these and other factors is a worthwhile endeavor. However, understanding how executive function develops and can be improved requires taking into account that executive function is always engaged in the service of a particular goal, whether in the lab or in the wild. These goals activate mental content that shapes how executive function is engaged and develops in relation to particular situations.

\section{Implications of this view}

The current proposal would have limited value if it were simply another way of thinking about executive function that didn't better explain the data or generate testable hypotheses that favor the theory. Next I summarize a variety of implications of this account and related predictions.

New ideas about how executive function development relates to other developmental phenomena

On the proposed account, correlations between canonical executive function measures and measures of domain-specific abilities such as theory of mind do not reflect the mechanistic role of executive function components, but rather indicate that both types of measures assess control engaged in the service of particular goals, achieved via the activation of relevant knowledge, beliefs, and more (Figure 2). The relation between false belief and executive function, for example, has often been explained in terms of the mechanistic role that executive function components play in the expression or emergence of theory of mind understanding. On these accounts, executive function components are thought to be necessary for the expression of existing conceptual knowledge (e.g., inhibiting one's own knowledge state when needing to respond on the basis of another's belief state, Baillargeon, Scott, \& He, 2010; Powell \& Carey, 
2017) or the acquisition of that knowledge (Benson, Sabbagh, Carlson, \& Zelazo, 2012). On the proposed account, however, executive function and false belief reasoning are much more entwined: thinking through the correct response on a false belief task occurs through the engagement of control, and engaging control in this context is achieved in part through the activation of relevant knowledge, such as that conferred by prior opportunities to think about others' mental states. For example, a child may have learned through experience that others can prefer foods that they themselves do not like, and they may have had this experience in relation to a particular individual, like a sibling. This knowledge should help the child to engage control to choose a food for their sibling that they themselves do not like versus giving a food that they like but the sibling doesn't (Repacholi \& Gopnik, 1997). On the other hand, they may fail to effectively engage control on another version of this task that doesn't activate relevant mental state knowledge that they can draw upon, for example, when asked to choose a food for an unfamiliar creature.

A)

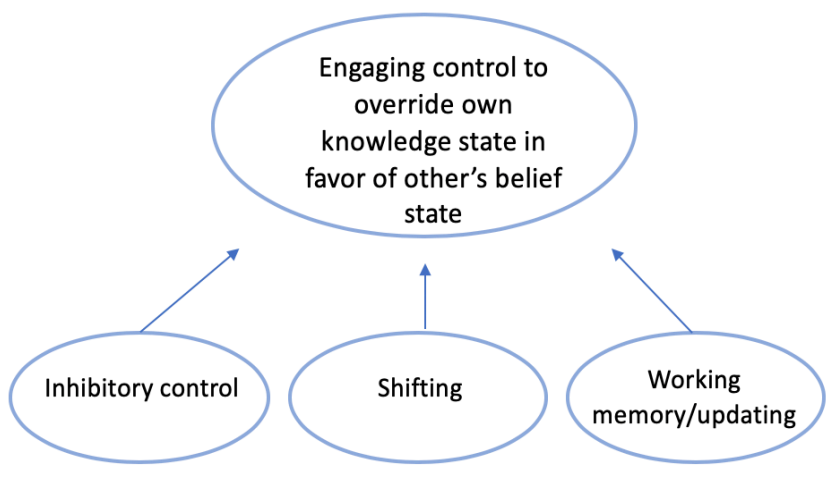

B)

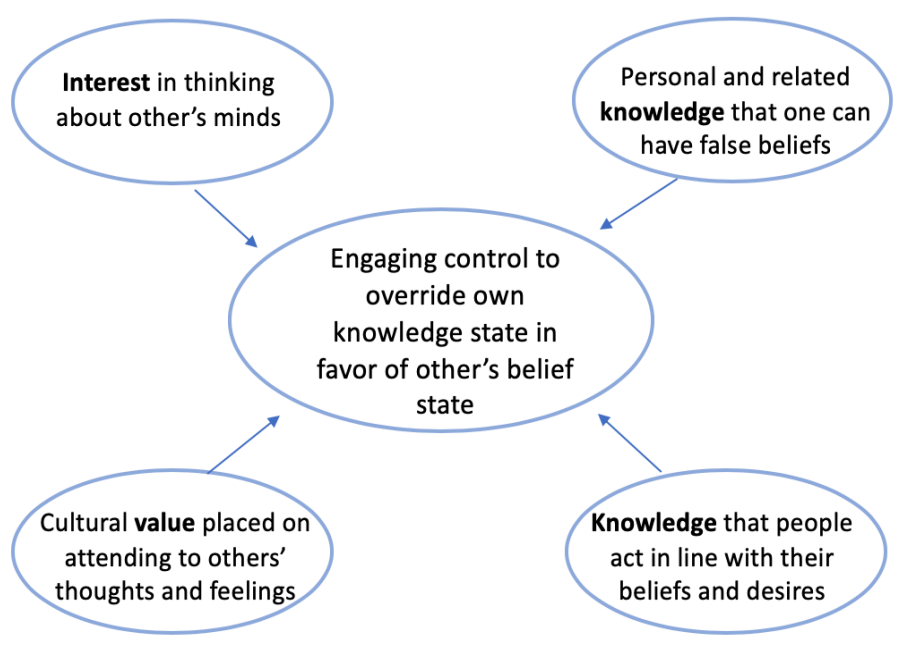

Figure 2. Contrasting views of how executive function relates to false belief reasoning. (A): Diagram of the view that executive function component processes mechanistically support false belief reasoning. For example, on one version of the 'expressionist' view, developing inhibitory control allows one to express their existing competence at false belief reasoning. (B): Diagram of proposed view, where engaging control to exercise false belief reasoning is supported by various kinds of mental content acquired with development, like personal and related knowledge about false beliefs. 
Conversely, mental state knowledge may support performance on some executive function tasks, which may partially account for some of the correlational findings between performance on theory of mind and executive function tasks. For example, with age some children may increasingly perceive that the experimenter desires that they perform well on the task, which may interact with their own values (e.g., complying with other's wishes) and thereby influence how they approach the task goal. While prior work has not found a relation between children's executive function task performance and understanding that different people can have different desires (Henning, Spinath, \& Aschersleben, 2011), on the proposed view it is not an understanding of diverse desires that supports children's use of executive function in various contexts, but rather children's tendency to think about desire states generally, which is likely shaped by their experience learning about their own and others' desires.

This account explains a range of findings in the literature, including cross-cultural findings of dissociations between theory of mind and executive function. Chinese children perform better than US children on lab executive function tasks but not on theory mind tasks (Sabbagh, Xu, Carlson, Moses, \& Lee, 2006), which may be because Chinese children are better equipped with knowledge and values that support using executive control on lab executive function tasks (e.g., stronger cultural values related to complying with others' requests, Chen et al., 2003), but are not as well equipped with mental state knowledge that supports the use of control on theory of mind tasks (e.g., less experiential knowledge of others' mental states, perhaps due to fewer siblings, Perner, Ruffman, \& Leekham, 1994; Sabbagh et al., 2006). Moreover, providing children with experience with false beliefs (their own and those of others) improves false belief task performance (e.g., Hale \& Flusberg, Gopnik \& Slaughter, 2003; Lohmann \& Tomasello, 2003). Children are also more likely to pass false belief tasks when 
knowledge of their own prior (false) belief state is cued (Freeman \& Lacohée, 1995) or when the experimenter explicitly highlights the protagonist's false belief (Wellman et al., 2001). This pattern of findings is consistent with the notion that rich knowledge about mental states is part of what enables children to effectively engage executive function to think from another's perspective and override their own. ${ }^{3}$

This account makes several predictions related to theory of mind and executive function that can be tested in future work, a few of which are described briefly. One is that children with more experiential knowledge related to false belief should be able to engage control better on false belief tasks, as indexed by online behavioral or physiological measures of executive function (e.g., reaction time and pupillometry indices). By contrast, engaging executive function via lab executive function tasks or other activities shouldn't help children on false belief tasks. Children should also perform better on executive function tasks when the experimenter's desire or value states are highlighted. Similarly, providing training in understanding others' desires and values may confer benefits to performance on some untrained executive function tasks that involve an experimenter delivering instructions, while standard training of putative executive function components would not be expected to.

New ideas about how executive function development relates to self-regulation broadly

\footnotetext{
${ }^{3}$ The proposed account can also explain the asymmetry found in predictive relations between false belief and executive function tasks, where executive function task performance predicts later false belief (controlling for concurrent false belief) but false belief does not predict later executive function task performance (controlling for concurrent executive function performance) (Devine \& Hughes, 2014; Marcovitch, O’Brien, Calkins, Leerkes, Weaver, et al., 2015). On the current proposal, it is not expected that variance on false belief tasks will account for later executive function because the mental state knowledge that may be engaged in executive function tasks may not be the same kind of knowledge tapped in false belief tasks (i.e., other's desires vs. their discrepant knowledge states).
} 
This proposal also provides a new explanation of the relation between lab and questionnaire assessments that accounts for findings that performance on executive function tasks does not consistently relate to scores questionnaires (e.g., Eisenberg et al., 2019; Toplak et al., 2013). Rather than executive function components mechanistically supporting self-regulation as assessed by questionnaires (or lab tasks and questionnaires tapping entirely different constructs, as has been recently suggested, Friedman \& Banich, 2019; Eisenberg et al., 2019; Enkavi et al., 2019), lab tasks and questionnaires assess control engaged in very different ways with different kinds of knowledge, beliefs, values and so on, coming into play. For example, the card sort assesses a child's success at engaging control in the service of shifting between sorting by color and shape dimensions, whereas a questionnaire asking about a child's ability to shift from one activity or situation to another likely assesses control used in the service of typical classroom or home activities (Gioia, Isquith, Guy, \& Kenworthy, 2000). On this view, it's not surprising that scores on these different measures are not always related. On the other hand, different patterns may emerge when executive function is operationalized as a composite or latent variable (e.g., 'common EF'), which may more sensitively tap the capacity for executive function (Freidman \& Miyake, 2012). Here correlations with questionnaire measures may still be inconsistent because questionnaires may not get at variance in capacity so much as variance in skills in using executive function in life outside the lab. However, in clinical samples there may be stronger relations between latent variables and composites on the one hand, and questionnaires and outcomes on the other, as it may be harder to develop skills in using executive function when executive function capacity is impaired because of neurological disorders. New challenges to developmental theories of executive function 
On the current proposal, neurocognitive developmental accounts of executive function do not adequately take into account that executive function is always used in relation to specific goals that affect how it is used and develops. That is, instead of proposed mechanisms like reflection or maintenance of abstract representations driving general developments in executive function, I propose that skills in using executive function develop in relation to specific goals, through the acquisition of various kinds of mental content like knowledge, beliefs, and values that support its use.

For example, one enduring account of executive function development posits a critical role for increases in the capacity for reflection (Zelazo, 2004). While reflection may be critical to engaging executive function in many contexts and neurologically-based deficits may be characterized by poor reflection, the propensity for reflection may vary greatly depending on the relevant mental content the child can bring bear on a specific goal. It has been argued, for example, that children successfully switch on the card sort when they can reflect on the structure of the task and recognize that there are two conflicting ways of sorting the test cards (e.g., by color or shape) (Zelazo, 2004). I suggest this may occur in part through specific conceptual knowledge involved in the task - e.g., of the dimensions shape and color. Viewing such influences as idiosyncratic to the task misses the point; in all executive function tasks - in the lab and beyond it - conceptual and other knowledge may be key to reflecting and engaging control. Importantly, there may be variation in the cultural knowledge, beliefs, and values that children learn that can support reflection and using executive function in various contexts (Doebel et al., 2019; Lamm et al., 2018; Lillard, 2016; Obradovic, et al., 2019). Thus, instead of training children to reflect during executive function lab tasks (e.g, Espinet, Anderson, \& Zelazo, 2013; Zelazo, Forston, Masten, \& Carlson, 2018) it may be more fruitful to provide children with 
experiences that could help them value using control more, which may, in turn, improve their awareness of the need for control in critical moments. Similarly, children who gain extensive concrete experience learning about shape and color dimensions in their preschool classrooms (like children in Montessori preschools) may perform better on the card sort than children in play-based preschools, in part because they are more capable of reflecting on diverse aspects of the task at hand and engaging control accordingly (Lillard, 2016).

Another prominent view is that executive function improves through general, prefrontally-supported increases in robust abstract representations in working memory (Munakata, Snyder, \& Chatham, 2012; Morton \& Munakata, 2002). However, on the proposed view, the capacity to maintain abstract representations in working memory will vary depending on the specific goal at hand and the availability of relevant mental content that could enhance the meaningfulness of the goal for the child and support them in engaging control. For example, with age children improve in how proactively they engage control on certain tasks, which has been explained in terms of developmental changes in the capacity to maintain goal information (Chatham, Frank, \& Munakata, 2012; Munakata, et al., 2012). A contrasting hypothesis stemming from the proposed account is that children will learn to engage control proactively if they have relevant knowledge, values, beliefs and so on to support doing so. For example, if the child has the goal of completing a foot race as quickly as possible, they may engage control early and prepare (i.e., getting into the right stance and listening carefully for a signal) if they have knowledge that doing so benefits running performance (e.g., from observing or listening to others), or if they believe that running fast will please their friends or family, or if it's normative in their community to compete fiercely, or if they value planning ahead generally, etc. Here, the failure to engage control proactively isn't explained in terms of a general developmental 
neurocognitive constraint in activating and maintaining goal representations, but rather in terms of the availability of relevant information that the child can draw on to support their effective engagement of control. On this view, what develops in typical children isn't best thought of as a general, content-free capacity to maintain abstract representations, but rather skills in engaging control capacity strategically in the service of countless specific goals that are increasingly meaningful in light of acquired knowledge, beliefs, values, and other mental content.

This account also contrasts with the proposal that there are distinct 'hot' and 'cool' executive function processes, with hot processes supporting the use of executive function in affectively and motivationally significant contexts (Zelazo \& Carlson, 2012). This hot/cool distinction is supported by differential performance on tasks that have face validity as hot vs. cool tasks, evidence of distinct but overlapping neural systems, and a conceptual analysis that would suggest that so-called 'cool' tasks are devoid of affective and motivational context (Zelazo \& Carlson, 2012). On the proposed account, however, this dichotomized view, while elegantly accounting for and describing many findings, oversimplifies how affect and motivation shape executive function engagement. Rather than classifying tasks as 'hot' or 'cool', it is critical to take into account the nature of the specific goal when seeking to understand and predict children's performance. Even on canonical child lab tasks like the Dimensional Change Card Sort there are representations with affective and motivational properties that come into play that influence performance and skill. A child may maintain the task goal more robustly if they value using control and doing well on tasks assigned by others, or if they believe that their performance on the task matters to someone like a parent, sibling, or the experimenter, or if they have knowledge that they bring to the task that makes it more meaningful and exciting (e.g., prior extensive experience sorting by shapes and colors). The point is not that these variables will 
explain children's performance on the task entirely, but that it is unlikely that executive function can ever be engaged without there being any notable motivational or affective significance for the child. Similarly, the influence of 'hot' task contexts involving social stimuli or cues will vary depending on how the social content relates to the goal. For example, perform better on an ostensibly 'hot' executive function task - the marshmallow test - when told that a peer group waited for two marshmallows and an outgroup didn't compared to children who were told the opposite (Doebel \& Munakata, 2018). Thus, the current account predicts that there aren't general developmental differences in performance on 'hot' vs. 'cool' tasks that are supported by distinct underlying mechanisms, but rather executive function performance will vary depending on the specific goal at hand and the mental content it evokes.

\section{New ideas about interventions to improve executive function}

Future executive function interventions can try to influence it with a view to specific goals and related knowledge, beliefs, values, and more. So if one is interested in supporting executive function development in the preschool classroom, for example, it will be useful to consider the specific goals of interest (e.g., talking about feelings instead of crying or hitting, cleaning up when playtime is over instead of continuing to play), and target the various kinds of knowledge, norms, values, and interests that may support their pursuit and achievement. Similarly, parenting interventions to support executive function, which until now have tended to be quite broad (e.g., covering things as disparate as positive parenting and nutrition, Obradovic et al., 2019), could zero in on aspects of parenting and socialization processes that may be more likely to help children engage executive function in the service of particular goals.

A related prediction is that providing values-based training (e.g., teaching children about the value of using control in different situations through language, stories, modeling, etc.) may 
have a broader impact on executive function than exercising executive function components on lab tasks or parenting interventions designed to improve executive function components through general support for brain development.

Interventions should also take into account that the same goals can activate different knowledge, beliefs, and values in different children, for example in children from different socioeconomic (SES) backgrounds. As discussed, it is common in the field to assume that poor task performance in children of lower SES backgrounds is primarily a function of "deficits" induced by disparity in support for brain development. However, beliefs, values, and other mental content may also shape these children's performance on executive function measures. For example, a belief that the environment and the people in it are not reliable may affect how well control is engaged in particular contexts (Kidd, et al., 2013; Michaelson \& Munakata, 2016; Ma, Chen, $\mathrm{Xu}$, Lee, \& Heyman, 2018). Children may also struggle to use control in contexts that have questionable significance for them in part because of the absence of prior experience to suggest that rewards are forthcoming (Michaelson \& Munakata, in press; Pepper \& Nettle, 2018). They may also have limited experience with researchers, so any mental state reasoning about what experimenter wants or values may be disrupted. Conceptual knowledge may also vary by SES, which seems plausible given what is known about SES differences in language development (Hoff, 2003; Rowe, 2008). For example, children from higher SES backgrounds may be provided with more opportunities to learn about a range of concepts (e.g., shape, color, number, mental states) that can support engaging executive function in myriad ways. Children from higher SES backgrounds may also be more often exposed to regulatory language that may help them acquire and subsequently activate representations of rules and norms related to various goals (Vygotsky, 2012/1934). 
Children with executive function deficits that are linked to neurological impairments could also potentially benefit from interventions that target relevant mental content like knowledge, values, and beliefs that could make it easier for them to use their capacity for executive control to good effect. Conversely, interventions should also target factors that may have effects on executive function capacity (e.g., noise, sleep, television, and nutrition, Carter et al., 2010; Erikson \& Newman, 2017; Lillard, et al., 2015; Turnbull, Reid, \& Morton, 2013) and that may make it difficult for children to acquire and put into practice knowledge, norms, values, and more that support the use of executive function in particular contexts.

\section{New ideas about measuring executive function}

Age-related improvements on executive function lab tasks like the Dimensional Change Card Sort are among the most robust findings in developmental psychology. But the current proposal suggests that we ought to think about how we can measure executive function in more ecologically valid ways rather than measuring it using standard lab tasks and extrapolating to real world functioning. That is, rather than assuming that the lab tasks measure component processes that mechanistically support real world functioning, we should aim to measure executive function in ways that are more relevant to specific outcomes of interest beyond the lab (see Enkavi et al., 2019 for a similar point). For example, instead of asking children to inhibit pressing a button on a screen, they could be asked to inhibit touching attractive unattended toys on display for a period of time, or to periodically switch between practical tasks. Tasks along these lines have been developed (e.g., Carlson, 2005) but are not as widely used as tasks like the DCCS and Day-Night task, perhaps in part because of the belief that the latter kind of tasks are "purer" indices of putative executive function components. 
Advocating for more ecologically valid measures does not imply we should abandon standard lab measures or particular classes of measures (e.g., shifting or working memory tasks). The tasks one uses depends on one's research goals (Enkavi et al., 2019; Miyake \& Friedman, 2012). Standard tasks have has been found to predict independent variance in outcomes compared to questionnaires (Friedman \& Banich, 2019), and specific task classes have been found to differentially relate to different outcomes (Bernier, Carlson, Deschênes, \& MatteGagné, 2011; Carlson \& Moses, 2001; Miyake et al., 2000; Friedman et al., 2006). The argument here is simply that one shouldn't assume that these standard measures are capturing executive function most purely or in ways that are highly relevant for real world outcomes.

\section{Conclusion}

Executive function development is critical to a broad range of human capacities, skills, and achievements, and the capacity for executive function is supported by prefrontal cortical integrity and a wide range of factors that influence it. But the notion that executive function development can be characterized as improvement in a few components is not justified conceptually or empirically, and fails to properly acknowledge that executive function is always engaged in the service of particular goals that activate and are influenced by diverse mental content such as knowledge, beliefs, and values. Future work should avoid reifying executive function as components. This account generates numerous predictions about the nature of executive function development and how it relates to other developmental phenomena that should be tested in future work. Key challenges for the field are: understanding more about how knowledge, values, beliefs, and other mental content shape how children engage control, and how these factors may partially explain group, developmental, and individual differences in control; developing more ecologically valid measures that are tailored to research questions and 
outcomes of interest; and creating interventions that take into account specific goals and contexts to support executive function skill development in diverse children.

\section{Acknowledgements}

I thank two reviewers for their constructive and thorough feedback on early versions of the manuscript. I also thank those with whom I've had many discussions on topics addressed in these pages, including Jane Barker, Laura Michaelson, Akira Miyake, Yuko Munakata, Nicole Stucke, Claudia von Bastian, and Phil Zelazo. 


\section{References}

Alderson-Day, B., \& Fernyhough, C. (2015). Inner speech: development, cognitive functions, phenomenology, and neurobiology. Psychological Bulletin, 141(5), 931-965.

Baddeley, A. D., \& Hitch, G. (1974). Working memory. In Psychology of learning and motivation (Vol. 8, pp. 47-89). Academic press.

Berkman, E. T., Hutcherson, C. A., Livingston, J. L., Kahn, L. E., \& Inzlicht, M. (2017). Selfcontrol as value-based choice. Current Directions in Psychological Science, 26(5), $422-$ 428.

Bernier, A., Carlson, S. M., Deschênes, M., \& Matte-Gagné, C. (2012). Social factors in the development of early executive functioning: A closer look at the caregiving environment. Developmental Science, 15(1), 12-24.

Best, J. R., \& Miller, P. H. (2010). A developmental perspective on executive function. Child Development, 81(6), 1641-1660.

Best, J. R., Miller, P. H., \& Naglieri, J. A. (2011). Relations between executive function and academic achievement from ages 5 to 17 in a large, representative national sample. Learning and Individual Differences, 21(4), 327-336.

Baillargeon, R., Scott, R. M., \& He, Z. (2010). False-belief understanding in infants. Trends in Cognitive Sciences, 14(3), 110-118.

Bialystok, E. (2001). Bilingualism in development: Language, literacy, and cognition. Cambridge University Press.

Benson, J. E., Sabbagh, M. A., Carlson, S. M., \& Zelazo, P. D. (2013). Individual differences in executive functioning predict preschoolers' improvement from theory-of-mind 
training. Developmental Psychology, 49(9), 1615-1627.

Blair, C., \& Razza, R. P. (2007). Relating effortful control, executive function, and false belief understanding to emerging math and literacy ability in kindergarten. Child Development, 78(2), 647-663.

Bodrova, E., \& Leong, D. J. (2006). Tools of the mind. Pearson Australia Pty Limited.

Bull, R., Espy, K. A., Wiebe, S. A., Sheffield, T. D., \& Nelson, J. M. (2011). Using confirmatory factor analysis to understand executive control in preschool children: Sources of variation in emergent mathematic achievement. Developmental Science, 14(4), 679-692.

Bunge, S. A., \& Zelazo, P. D. (2006). A brain-based account of the development of rule use in childhood. Current Directions in Psychological Science, 15(3), 118-121.

Buss, A. T., \& Spencer, J. P. (2014). The emergent executive: A dynamic field theory of the development of executive function. Monographs of the Society for Research in Child Development, 79(2), vii.

Buss, A. T., \& Spencer, J. P. (2018). Changes in frontal and posterior cortical activity underlie the early emergence of executive function. Developmental Science, 21(4), e12602.

Carlson, S. M., \& Moses, L. J. (2001). Individual differences in inhibitory control and children's theory of mind. Child Development, 72(4), 1032-1053.

Carlson, S. M., \& Zelazo, P. D. (2011). The value of control and the influence of values. Proceedings of the National Academy of Sciences, 108, 16861-16862.

Carter, R. C., Jacobson, J. L., Burden, M. J., Armony-Sivan, R., Dodge, N. C., Angelilli, M. L., ... \& Jacobson, S. W. (2010). Iron deficiency anemia and cognitive function in infancy. Pediatrics, 126(2), e427-e434.

Chen, X., Rubin, K., Liu, M., Chen, H., Wang, L., Li, D., .. \& Li, B. (2003). Compliance in 
Chinese and Canadian toddlers: A cross-cultural study. International Journal of Behavioral Development, 27(5), 428-436.

Damasio, H., Grabowski, T., Frank, R., Galaburda, A. M., \& Damasio, A. R. (1994). The return of Phineas Gage: clues about the brain from the skull of a famous patient. Science, 264(5162), 1102-1105.

Demakis, G. J. (2003). A meta-analytic review of the sensitivity of the Wisconsin Card Sorting Test to frontal and lateralized frontal brain damage. Neuropsychology, 17(2), 255.

Devine, R. T., \& Hughes, C. (2014). Relations between false belief understanding and executive function in early childhood: A meta-analysis. Child Development, 85(5), 1777-1794.

De Simoni, C., \& von Bastian, C. C. (2018). Working memory updating and binding training: Bayesian evidence supporting the absence of transfer. Journal of Experimental Psychology: General, 147(6), 829.

Diamond, A. (2012). Activities and programs that improve children's executive functions. Current Directions in Psychological Science, 21(5), 335-341.

Diamond, A. (2013). Executive functions. Annual Review of Psychology, 64, 135-168.

Diamond, A., Barnett, W. S., Thomas, J., \& Munro, S. (2007). Preschool program improves cognitive control. Science, 318(5855), 1387-1388.

Doebel, S., Dickerson, J. P., Hoover, J. D., \& Munakata, Y. (2018). Using language to get ready: Familiar labels help children engage proactive control. Journal of Experimental Child Psychology, 166, 147-159.

Doebel, S., Rowell, S. F., \& Koenig, M. A. (2016). Young children detect and avoid logically inconsistent sources: The importance of communicative context and executive function. Child Development, 87(6), 1956-1970. 
Doebel, S., \& Munakata, Y. (2018). Group influences on engaging self-control: Children delay gratification and value it more when their in-group delays and their out-group doesn't. Psychological Science, 29(5), 738-748.

Doebel, S., \& Zelazo, P. D. (2015). A meta-analysis of the Dimensional Change Card Sort: Implications for developmental theories and the measurement of executive function in children. Developmental Review, 38, 241-268.

Duckworth, A. L., \& Kern, M. L. (2011). A meta-analysis of the convergent validity of selfcontrol measures. Journal of Research in Personality, 45, 259-268.

Erickson, L. C., \& Newman, R. S. (2017). Influences of background noise on infants and children. Current Directions in Psychological Science, 26(5), 451-457.

Eisenberg, I. W., Bissett, P. G., Enkavi, A. Z., Li, J., MacKinnon, D. P., Marsch, L. A., \& Poldrack, R. A. (2019). Uncovering the structure of self-regulation through data-driven ontology discovery. Nature Communications, 10(1), 2319.

Enkavi, A. Z., Eisenberg, I. W., Bissett, P. G., Mazza, G. L., MacKinnon, D. P., Marsch, L. A., \& Poldrack, R. A. (2019). Reply to Friedman and Banich: Right measures for the research question. Proceedings of the National Academy of Sciences, 116(49), 2439824399.

Espinet, S. D., Anderson, J. E., \& Zelazo, P. D. (2013). Reflection training improves executive function in preschool-age children: Behavioral and neural effects. Developmental Cognitive Neuroscience, 4, 3-15.

Freeman, N. H., \& Lacohée, H. (1995). Making explicit 3-year-olds' implicit competence with their own false beliefs. Cognition, 56(1), 31-60.

Friedman, N. P., \& Banich, M. T. (2019). Questionnaires and task-based measures assess 
different aspects of self-regulation: Both are needed. Proceedings of the National Academy of Sciences, 116(49), 24396-24397.

Friedman, N. P., Miyake, A., Young, S. E., DeFries, J. C., Corley, R. P., \& Hewitt, J. K. (2008). Individual differences in executive functions are almost entirely genetic in origin. Journal of Experimental Psychology: General, 137(2), 201-225.

Friedman, N. P., Miyake, A., Robinson, J. L., \& Hewitt, J. K. (2011). Developmental trajectories in toddlers' self-restraint predict individual differences in executive functions 14 years later: A behavioral genetic analysis. Developmental psychology, 47(5), 1410.

Miyake, A., \& Friedman, N. P. (2012). The nature and organization of individual differences in executive functions: Four general conclusions. Current Directions in Psychological Science, 21(1), 8-14.

Gärtner, A., \& Strobel, A. (2019). Individual differences in inhibitory control: A latent variable analysis. Unpublished manuscript. https://psyarxiv.com/gnhmt/

Gerstadt, C. L., Hong, Y. J., \& Diamond, A. (1994). The relationship between cognition and action: performance of children 312-7 years old on a stroop-like day-night test. Cognition, 53(2), 129-153.

Goldstein, T. R., \& Lerner, M. D. (2018). Dramatic pretend play games uniquely improve emotional control in young children. Developmental Science, 21(4), e12603.

Hackman, D. A., Gallop, R., Evans, G. W., \& Farah, M. J. (2015). Socioeconomic status and executive function: Developmental trajectories and mediation. Developmental Science, 18(5), 686-702.

Hale, C. M., \& Tager-Flusberg, H. (2003). The influence of language on theory of mind: A training study. Developmental Science, 6(3), 346-359. 
Slaughter, V., \& Gopnik, A. (1996). Conceptual coherence in the child's theory of mind: Training children to understand belief. Child Development, 67(6), 2967-2988.

Henning, A., Spinath, F. M., \& Aschersleben, G. (2011). The link between preschoolers' executive function and theory of mind and the role of epistemic states. Journal of Experimental Child Psychology, 108(3), 513-531.

Hodel, A. S. (2018). Rapid infant prefrontal cortex development and sensitivity to early environmental experience. Developmental Review, 48, 113-144.

Hoff, E. (2003). The specificity of environmental influence: Socioeconomic status affects early vocabulary development via maternal speech. Child Development, 74(5), 1368-1378.

Huizinga, M., Dolan, C. V., \& van der Molen, M. W. (2006). Age-related change in executive function: Developmental trends and a latent variable analysis. Neuropsychologia, 44(11), 2017-2036.

Johann, V. E., \& Karbach, J. (2019). Effects of game-based and standard executive control training on cognitive and academic abilities in elementary school children. Developmental Science, e12866.

Karr, J. E., Areshenkoff, C. N., Rast, P., Hofer, S. M., Iverson, G. L., \& Garcia-Barrera, M. A. (2018). The unity and diversity of executive functions: A systematic review and reanalysis of latent variable studies. Psychological Bulletin, 144(11), 1147.

Kassai, R., Futo, J., Demetrovics, Z., \& Takacs, Z. K. (2019). A meta-analysis of the experimental evidence on the near-and far-transfer effects among children's executive function skills. Psychological Bulletin, 145(2), 165.

Kidd, C., Palmeri, H., \& Aslin, R. N. (2013). Rational snacking: Young children's 
decision-making on the marshmallow task is moderated by beliefs about environmental reliability. Cognition, 126(1), 109-114.

Kirkham, N. Z., Cruess, L., \& Diamond, A. (2003). Helping children apply their knowledge to their behavior on a dimension-switching task. Developmental Science, 6(5), $449-467$.

Lamm, B., Keller, H., Teiser, J., Gudi, H., Yovsi, R. D., Freitag, C., ... \& Vöhringer, I. (2018). Waiting for the second treat: Developing culture-specific modes of selfregulation. Child Development, 89(3), e261-e277.

Leonard, J. A., Lee, Y., \& Schulz, L. E. (2017). Infants make more attempts to achieve a goal when they see adults persist. Science, 357(6357), 1290-1294.

Lillard, A. S., Lerner, M. D., Hopkins, E. J., Dore, R. A., Smith, E. D., \& Palmquist, C. M. (2013). The impact of pretend play on children's development: A review of the evidence. Psychological Bulletin, 139(1), 1.

Lillard, A. S., Drell, M. B., Richey, E. M., Boguszewski, K., \& Smith, E. D. (2015). Further examination of the immediate impact of television on children's executive function. Developmental Psychology, 51(6), 792.

Lillard, A. S. (2016). Montessori: The science behind the genius. Oxford University Press.

Lohmann, H., \& Tomasello, M. (2003). The role of language in the development of false belief understanding: A training study. Child development, 74(4), 1130-1144.

Ma, F., Chen, B., Xu, F., Lee, K., \& Heyman, G. D. (2018). Generalized trust predicts young children's willingness to delay gratification. Journal of Experimental Child Psychology, 169, 118-125. 
Marcovitch, S., \& Zelazo, P. D. (2009). A hierarchical competing systems model of the emergence and early development of executive function. Developmental science, 12(1), $1-18$.

Mercer, J. (2011). Martial arts research: Weak evidence. Science, 334(6054), 310-311.

Michaelson, L. E., \& Munakata, Y. (2016). Trust matters: Seeing how an adult treats another person influences preschoolers' willingness to delay gratification. Developmental Science, 19(6), 1011-1019.

Michaelson, L., \& Munakata, Y. (in press). Same dataset, different conclusions: Preschool delay of gratification predicts later behavioral outcomes in a preregistered study. Psychological Science.

Miyake, A., Friedman, N. P., Emerson, M. J., Witzki, A. H., Howerter, A., \& Wager, T. D. (2000). The unity and diversity of executive functions and their contributions to complex "frontal lobe" tasks: A latent variable analysis. Cognitive Psychology, 41(1), 49100.

Miyake, A., \& Friedman, N. P. (2012). The nature and organization of individual differences in executive functions: Four general conclusions. Current Directions in Psychological Science, 21(1), 8-14.

Montgomery, D. E., \& Koeltzow, T. E. (2010). A review of the day-night task: The Stroop paradigm and interference control in young children. Developmental Review, 30(3), 308330.

Munakata, Y., Snyder, H. R., \& Chatham, C. H. (2012). Developing cognitive control: Three key transitions. Current Directions in Psychological Science, 21(2), 71-77.

Noble, K. G. (2017). Brain Trust. Scientific American. 
Obradović, J., Finch, J. E., Portilla, X., Rasheed, M., Tirado-Strayer, N., Yousafzai, A. (2019). Early executive functioning in a global context: Developmental continuity and family protective factors. Developmental Science. Advance Online Publication

Pennington, B. F., \& Ozonoff, S. (1996). Executive functions and developmental psychopathology. Journal of Child Psychology and Psychiatry, 37(1), 51-87.

Pepper, G. V., \& Nettle, D. (2017). The behavioural constellation of deprivation: Causes and consequences. Behavioral and Brain Sciences, 40.

Perner, J., Ruffman, T., \& Leekam, S. R. (1994). Theory of mind is contagious: You catch it from your sibs. Child Development, 65(4), 1228-1238.

Peterson, J. B., Rothfleisch, J., Zelazo, P. D., \& Pihl, R. O. (1990). Acute alcohol intoxication and cognitive functioning. Journal of studies on alcohol, 51(2), 114-122.

Powell, L. J., \& Carey, S. (2017). Executive function depletion in children and its impact on theory of mind. Cognition, 164, 150-162.

Pozuelos, J. P., Combita, L. M., Abundis, A., Paz-Alonso, P. M., Conejero, Á., Guerra, S., \& Rueda, M. R. (2019). Metacognitive scaffolding boosts cognitive and neural benefits following executive attention training in children. Developmental Science, 22(2), e12756.

Richland, L. E., \& Burchinal, M. R. (2013). Early executive function predicts reasoning development. Psychological Science, 24, 87-92.

Riggs, N. R., Greenberg, M. T., Kusché, C. A., \& Pentz, M. A. (2006). The mediational role of neurocognition in the behavioral outcomes of a social-emotional prevention program in elementary school students: Effects of the PATHS curriculum. Prevention Science, 7(1), 91-102.

Rowe, M. L. (2008). Child-directed speech: Relation to socioeconomic status, knowledge of 
child development and child vocabulary skill. Journal of Child Language, 35(1), 185205.

Sabbagh, M. A., Xu, F., Carlson, S. M., Moses, L. J., \& Lee, K. (2006). The development of executive functioning and theory of mind: A comparison of Chinese and US preschoolers. Psychological Science, 17(1), 74-81.

Saunders, B., Milyavskaya, M., Etz, A., Randles, D., \& Inzlicht, M. (2018). Reported self-control is not meaningfully associated with inhibition-related executive function: A bayesian analysis. Collabra: Psychology, 4(1), 39.

Saxe, G. B. (1988). The mathematics of child street vendors. Child Development, 59, 1415-1425.

Simpson, A., \& Carroll, D. J. (2019). Understanding early inhibitory development: distinguishing two ways that children use inhibitory control. Child Development.

Snyder, H. R. (2013). Major depressive disorder is associated with broad impairments on neuropsychological measures of executive function: a meta-analysis and review. Psychological Bulletin, 139, 81.

Toplak, M. E., West, R. F., \& Stanovich, K. E. (2013). Practitioner review: Do performancebased measures and ratings of executive function assess the same construct?. Journal of Child Psychology and Psychiatry, 54, 131-143.

Turnbull, K., Reid, G. J., \& Morton, J. B. (2013). Behavioral sleep problems and their potential impact on developing executive function in children. Sleep, 36(7), 1077-1084.

von Bastian, C. C., Souza, A. S., \& Gade, M. (2016). No evidence for bilingual cognitive advantages: A test of four hypotheses. Journal of Experimental Psychology: General, 145(2), 246-258. https://doi.org/10.1037/xge0000120 
von Bastian, C. C., De Simoni, C., Kane, M., Carruth, N., \& Miyake, A. (2017). Does being bilingual entail advantages in working memory? A meta analysis. In 58th Annual Meeting of Psychonomic Society, Vancouver.

Vygotsky, L. (2012). Thought and language. Cambridge, MA: MIT Press. (Original work published 1934).

Wellman, H. M., Cross, D., \& Watson, J. (2001). Meta-analysis of theory-of-mind development: The truth about false belief. Child Development, 72(3), 655-684.

Westfall, J., \& Yarkoni, T. (2016). Statistically controlling for confounding constructs is harder than you think. PLOS ONE, 11(3), e0152719.

Wiebe, S. A., Espy, K. A., \& Charak, D. (2008). Using confirmatory factor analysis to understand executive control in preschool children: I. Latent structure. Developmental Psychology, 44(2), 575-587.

Wiebe, S. A., Sheffield, T., Nelson, J. M., Clark, C. A., Chevalier, N., \& Espy, K. A. (2011). The structure of executive function in 3-year-olds. Journal of Experimental Child Psychology, 108(3), 436-452.

Wilson, S. J., \& Farran, D. C. (2012). Experimental Evaluation of the Tools of the Mind Preschool Curriculum. Society for Research on Educational Effectiveness.

Winsler, A. E., Fernyhough, C. E., \& Montero, I. E. (2009). Private speech, executive functioning, and the development of verbal self-regulation. Cambridge University Press.

Zaitchik, D., Iqbal, Y., \& Carey, S. (2014). The effect of executive function on biological reasoning in young children: An individual differences study. Child Development, 85(1), $160-175$.

Zelazo, P. D. (2004). The development of conscious control in childhood. Trends in 
Cognitive Sciences, 8(1), 12-17.

Zelazo, P. D., Anderson, J. E., Richler, J., Wallner-Allen, K., Beaumont, J. L., \& Weintraub, S. (2013). II. NIH Toolbox Cognition Battery (CB): Measuring executive function and attention. Monographs of the Society for Research in Child Development, $78(4), 16-33$.

Zelazo, P. D. (2006). The Dimensional Change Card Sort (DCCS): A method of assessing executive function in children. Nature Protocols, 1(1), 297.

Zelazo, P. D., Forston, J. L., Masten, A. S., \& Carlson, S. M. (2018). Mindfulness plus reflection training: effects on executive function in early childhood. Frontiers in Psychology, 9, 208.

Zelazo, P. D., \& Carlson, S. M. (2012). Hot and cool executive function in childhood and adolescence: Development and plasticity. Child Development Perspectives, 6(4), 354360. 